\title{
Magnetic iron oxide nanoparticles as long wavelength photoinitiators for free radical polymerization $\uparrow$
}

1918

Received 1st December 2014,

Accepted 7th January 2015

DOI: $10.1039 /$ c4py01658k

www.rsc.org/polymers

\author{
Sajjad Dadashi-Silab, ${ }^{a}$ Yasemin Yar, ${ }^{b}$ Havva Yagci Acar ${ }^{\mathrm{b}}$ and Yusuf Yagci*a,c
}

Iron oxide nanoparticles $\left(\mathrm{Fe}_{3} \mathrm{O}_{4} \mathrm{NPs}\right)$ capped with lauric acid agents were synthesized and their photocatalytic activity was investigated in free radical photopolymerization of vinyl monomers. These NPs were able to release charge carriers (electronhole pairs) upon photoexcitation through which the capping agents or an additional amine co-initiator acting as the hole acceptor underwent oxidation to eventually form the initiating radicals. In lauric acid coated $\mathrm{Fe}_{3} \mathrm{O}_{4} \mathrm{NPs}$, electron transfer followed by a decarboxylation process accounts for the initiation.

Nanoscale materials have been the center of contemporary research in many interdisciplinary areas. Semiconductor nanoparticles (NPs) have been utilized for many catalytic purposes. Composed of transition-metal ions with group 15 or 16 ions as counter-anion components, inorganic semiconductor NPs are highly sensitive towards light and are able to release charge carriers upon photoexcitation. ${ }^{1}$ Numerous photocatalytic applications have been carried out employing semiconductor NPs as photocatalysts. Examples include water splitting to evolve hydrogen, ${ }^{2}$ biosensing, ${ }^{3}$ sensitizers in solar cells, ${ }^{4}$ remediation of pollutants and water purification, ${ }^{5,6}$ and many other photocatalytic processes. ${ }^{7,8}$ The photocatalytic activity is based on the excitation of semiconductor NPs under light and consequent formation of electron-hole pairs.

The (photo)polymer community has been interested in developing long wavelength ${ }^{9,10}$ photoinitiating systems working under mild conditions (e.g. the use of LED light sources $^{11}$ or oxygen tolerable systems ${ }^{12,13}$ ) with low energy

\footnotetext{
${ }^{a}$ Department of Chemistry, Istanbul Technical University, 34469 Maslak, Istanbul, Turkey. E-mail: yusuf@itu.edu.tr; Fax: +90-212285 6386; Tel: +90-212 2853241 ${ }^{b}$ Graduate School of Sciences and Engineering, Koc University, 34450 Sariyer, Istanbul, Turkey

${ }^{c}$ Center of Excellence for Advanced Materials Research (CEAMR) and Department of Chemistry, Faculty of Science, King Abdulaziz University, Jeddah, 21589, Saudi Arabia

$\dagger$ Electronic supplementary information (ESI) available: Details of experimental procedures, additional spectral data and ESI figures and table. See DOI: $10.1039 / \mathrm{c} 4 \mathrm{py} 01658 \mathrm{k}$
}

consumption. $^{14,15}$ As an example, semiconducting porous organic and inorganic nanoparticles (NPs) are being introduced as efficient photoinitiators in various photopolymerization fields. ${ }^{16-19}$ As early as 1966, Oster and co-workers reported the first example of semiconductor NP in photopolymerization using zinc oxide ( $\mathrm{ZnO}$ )-sensitized polymerization in aqueous media. $^{20}$ Hoffman et al. utilized quantum-sized $\mathrm{ZnO}$ as a photoinitiator in the polymerization of methyl methacrylate. ${ }^{21}$ The proposed mechanism involves the interaction of the photogenerated electrons and holes with the monomer and alcoholic solvent, respectively. They suggested an anionic initiation via the transfer of the excited electron to the monomer followed by free radical propagation by the formation of solvent radicals as a result of electron transfer from the alcohol to the photogenerated holes. Bulk-sized $\mathrm{ZnO}$ particles were not able to initiate the polymerization possibly due to the small surface/volume ratio decreasing the surface activity, small band gap and reduction potential. We have recently reported photoinitiated conventional ${ }^{22}$ and controlled radical $^{23}$ polymerizations using $\mathrm{ZnO}$ and iron doped zinc oxide $(\mathrm{Fe} / \mathrm{ZnO}) \mathrm{NPs}$. In the conventional photoinduced free radical polymerization, the process was accomplished by using an amine or iodonium salt co-initiator, in which oxidation of the amine followed by hydrogen abstraction formed the initiating radicals while in the case of iodonium salt, reduction of the ground state salt by photogenerated electrons gave rise to the corresponding initiating radicals. In the controlled photoinduced radical polymerization, photogenerated electrons from the NPs reduced copper(II) species to copper(I) which is the required copper catalyst for atom transfer radical polymerization (ATRP). Similar reduction processes to induce photoinitiation of ATRP have also been reported using various semiconducting materials. ${ }^{24-27}$

Several other studies regarding the use of semiconductor NPs including titanium dioxide $\left(\mathrm{TiO}_{2}\right)$, cadmium sulfide (CdS), iron oxide $\left(\mathrm{Fe}_{2} \mathrm{O}_{3}\right)$, and cadmium selenide (CdSe) NPs as photoinitiators in various photopolymerization systems have also been reported. ${ }^{28-32}$ In addition to the intrinsic distinctions in the nature of NPs, their photocatalytic activity can be 
tuned and controlled by adjusting the shape, size, and surface modification of NPs. ${ }^{33}$

Metal NPs were also utilized in photopolymerization systems. Neckers and co-workers investigated photopolymerization using thiol-stabilized gold (Au) NPs. ${ }^{34-36}$ They found that upon photoexcitation of Au NPs, electron transfer from NPs to the iodonium salt co-initiator, whose rate is dependent on the size of the NPs, decomposes the iodonium salt yielding free radicals to initiate polymerization. ${ }^{37}$ In this way, 2-3D conductive polymeric nanomaterials can be easily produced photochemically.

Despite great interest both in the photoinduced polymerization technique and nanoparticles separately, the potential of semiconductor NPs in photoinitiated polymerizations have not been fully addressed, understood or exploited yet and therefore, this area is open to many theoretical studies and potential applications.

In the present work, we report the use of modified magnetic iron oxide $\left(\mathrm{Fe}_{3} \mathrm{O}_{4}\right)$ NPs in the photoinitiation of free radical polymerization of vinyl monomers. These NPs were stabilized with acidic capping agents and the interaction of the photogenerated charge carriers upon photoexcitation of NPs led to the formation of the corresponding radicals to initiate the polymerization. Although these NPs acted as one-component photoinitiators through the interaction of photogenerated charge carriers with the capping agents, a conventional tertiary amine co-initiator, triethylamine (TEA), was supplemented to enhance the efficiency of the system.

Lauric acid (LA) coated $\mathrm{Fe}_{3} \mathrm{O}_{4} \mathrm{NPs}\left(\mathrm{Fe}_{3} \mathrm{O}_{4}\right.$-LA) were prepared according to a previously reported procedure. ${ }^{38}$ These particles are in the form of small clusters with an average hydrodynamic size of $58 \mathrm{~nm}$ in toluene (Fig. S1-S3, ESI $\dagger$ ). Chart 1 shows an illustration of $\mathrm{Fe}_{3} \mathrm{O}_{4}$-LA NPs and chemical structures of the coating agent LA and the co-initiator TEA used in the photopolymerization of vinyl monomers including methyl methacrylate (MMA), methyl acrylate (MA) and a polymeric monomer oligo(ethylene glycol) monomethyl ether methacrylate (OEOMA).

Synthesized NPs show strong absorption in UV and visible regions (Fig. 1). An extension of absorbance into the visible region in $\mathrm{Fe}_{3} \mathrm{O}_{4}$-LA, which is black-brown in color, is expected.

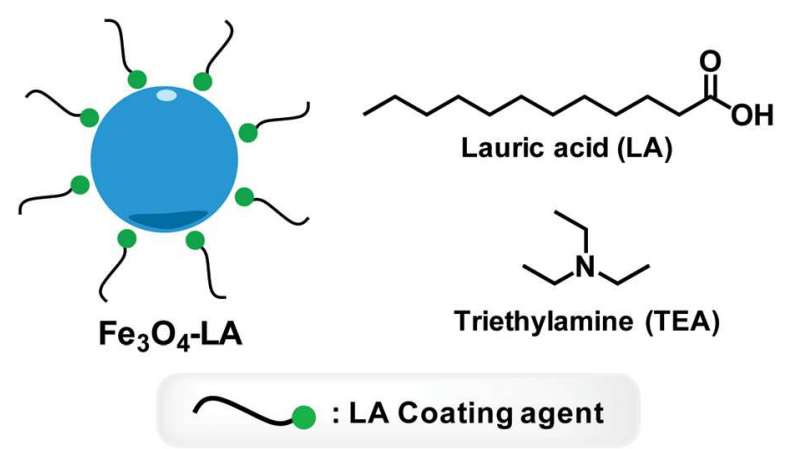

Chart 1 Illustration of modified iron oxide nanoparticles and chemical structures of the capping agent and the amine co-initiator.

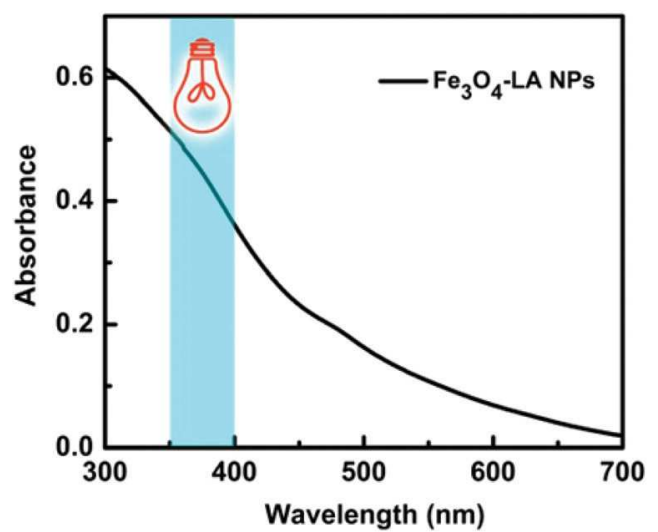

Fig. 1 UV-vis spectra of the $\mathrm{Fe}_{3} \mathrm{O}_{4}$-LA NPs in toluene ([NPs] $=1 \mathrm{mg}$ $\mathrm{mL}^{-1}$, path length $=10 \mathrm{~mm}$ ).

In order to evaluate the potential use of these NPs as photoinitiators in free radical systems, polymerizations of MMA, MA and OEOMA were attempted with and without a typical coinitiator, TEA under UV irradiation at $350 \mathrm{~nm}$. The system was capable of inducing photopolymerization in the absence of the co-initiator when illuminated at $350 \mathrm{~nm}$. Control experiments performed in the absence of NPs or in the dark confirmed the action of NPs and light as the origin of the photopolymerization. Addition of TEA to the polymerization mixture as the co-initiator enhanced the efficiency of the system in all monomers and provided higher conversions. Conversion and molecular weight analysis of these polymerizations are tabulated in Table 1. It is interesting to note that the MA monomer gave polymers with a much higher molecular weight which is entirely consistent with the usual assumptions that propagating MMA radicals terminate by (mainly) disproportionation whilst methyl acrylate-derived radicals terminate by combination.

In order to have a better understanding of the kinetics of photopolymerizations induced by these NPs, photocuring of triethylene glycol dimethacrylate (TEGDMA) with NPs was studied using photo-DSC. This monomer was chosen due to its less volatility suitable for photo-DSC measurements and a relatively comparable reactivity of its double bonds to MMA. Fig. 2 shows the time dependent polymerization rate and monomer conversion in the polymerization of TEGDMA using $\mathrm{Fe}_{3} \mathrm{O}_{4}$-LA NPS in the presence of a TEA co-initiator.

PhotoDSC measurements were also carried out with different light intensities (from 20 to $60 \mathrm{~mW} \mathrm{~cm}^{-2}$ ). Increasing the intensity of light increased the rate of the reaction and gave higher double bond conversions (Fig. 3). Obviously, intense light accelerates the formation of surface localized charge carriers and probably amplified the formation of charge carriers.

There has been a controversy in the literature regarding the exact mechanism of the photopolymerization initiated by semiconductor NPs. ${ }^{21,22,39,40}$ Based on the nature of the NPs and polymerization media (monomer, solvent, and coinitiator) several initiation mechanisms have been proposed. 
Table 1 Photopolymerization of vinyl monomers using magnetic iron oxide nanoparticles ${ }^{a}$

\begin{tabular}{|c|c|c|c|c|c|c|c|c|c|}
\hline \multirow[b]{3}{*}{ Run } & \multirow[b]{3}{*}{$\mathrm{Fe}_{3} \mathrm{O}_{4}$-LA NPs } & \multirow[b]{3}{*}{ Light } & \multirow[b]{3}{*}{ Monomer $^{b}$} & \multicolumn{6}{|l|}{ Co-initiator } \\
\hline & & & & \multicolumn{3}{|l|}{-} & \multicolumn{3}{|l|}{ TEA } \\
\hline & & & & Conv. $^{c}(\%)$ & $M_{\mathrm{n}} \times 10^{-3 d}\left(\mathrm{~g} \mathrm{~mol}^{-1}\right)$ & $M_{\mathrm{w}} / M_{\mathrm{n}}{ }^{d}$ & Conv. $^{c}(\%)$ & $M_{\mathrm{n}} \times 10^{-3 d}\left(\mathrm{~g} \mathrm{~mol}^{-1}\right)$ & $M_{\mathrm{w}} / M_{\mathrm{n}}^{d}$ \\
\hline 1 & - & + & MMA & - & - & - & - & - & - \\
\hline 2 & + & - & MMA & - & - & - & - & - & - \\
\hline 3 & + & + & MMA & 20 & 87.0 & 2.9 & 52 & 79.7 & 2.0 \\
\hline 5 & + & + & MA & 27 & 191.1 & 1.9 & 67 & 132.3 & 1.6 \\
\hline 6 & + & + & OEOMA & 17 & 70.6 & 1.3 & 45 & 145.4 & 1.5 \\
\hline
\end{tabular}

${ }^{a}$ Experimental conditions: $\lambda_{\text {irr }}=350 \mathrm{~nm}$, irradiation time: $5 \mathrm{~h},[\mathrm{M}]: 4.7 \mathrm{M}$, [TEA]: $0.1 \mathrm{M}, \mathrm{Fe}_{3} \mathrm{O}_{4}$-LA NPs: 23 mg, toluene: 1 mL. ${ }^{b}$ MMA: methyl

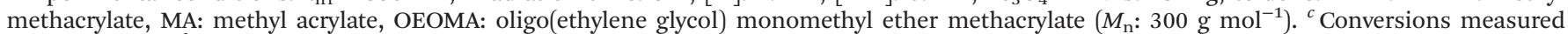
gravimetrically. ${ }^{d}$ Number-average molecular weight $\left(M_{\mathrm{n}}\right)$ and molecular weight distribution $\left(M_{\mathrm{w}} / M_{\mathrm{n}}\right)$ determined by GPC.

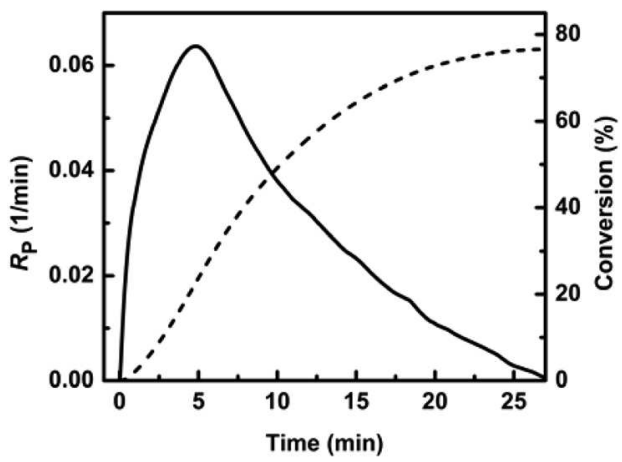

Fig. 2 Kinetics profile of the photopolymerization of triethylene glycol dimethacrylate using $\mathrm{Fe}_{3} \mathrm{O}_{4}$ - $\mathrm{LA}$ nanoparticles in the presence of the triethylamine co-initiator by means of photoDSC with the light intensity of $40 \mathrm{~mW} \mathrm{~cm}^{-2}$. Solid lines: rate of polymerization $\left(R_{\mathrm{P}}(1 / \mathrm{min})\right)$; dashed lines: double bond conversion (\%).

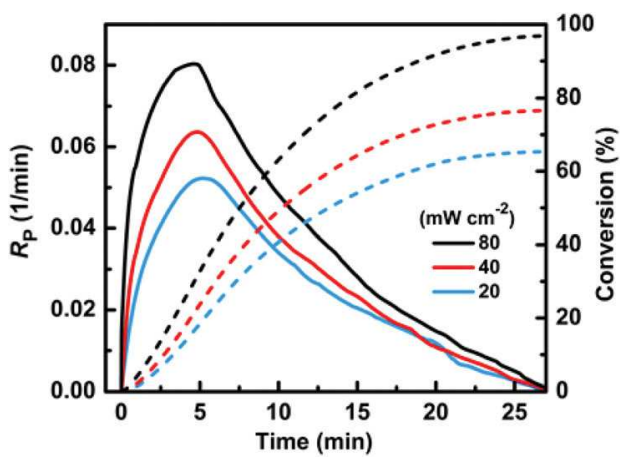

Fig. 3 Effect of light intensity on the kinetics of the photopolymerization of triethylene glycol dimethacrylate in the presence of the triethylamine co-initiator using $\mathrm{Fe}_{3} \mathrm{O}_{4}$-LA nanoparticles. Solid lines: rate of polymerization $\left(R_{\mathrm{P}}(1 / \mathrm{min})\right)$; dashed lines: double bond conversion (\%).

These include reduction/oxidation of the monomer or other components such as the surface modifier, co-initiator, and solvent by photogenerated electrons or holes. All these processes require appropriate matching of the reduction/oxidation potential of each compound with the band gap energy of the

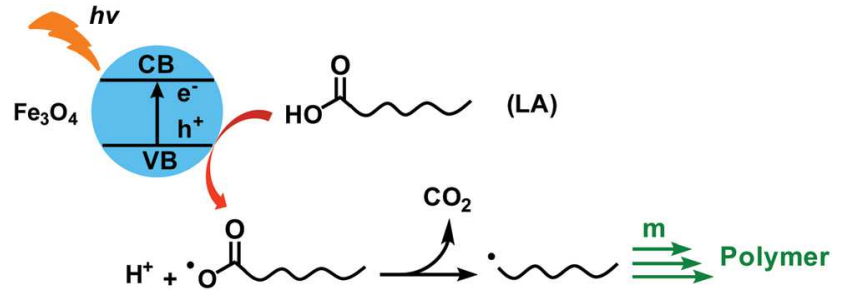

Scheme 1 Proposed initiation mechanism for the photopolymerization of vinyl monomers using $\mathrm{Fe}_{3} \mathrm{O}_{4}$ nanoparticles with the LA surface agent without additional co-initiators.

semiconductor. Oxidation of the amine co-initiators readily occurs by the photogenerated holes from the semiconductor while reduction is forbidden due to the unmatched difference in band gap energies. ${ }^{30}$

Oxidation of amine co-initiators to form free radicals in such systems was previously reported. ${ }^{16}$ This seems to be the dominant mechanism responsible for the formation of the initiating radicals.

In the absence of a co-initiator, the interaction between the holes and carboxylic acid groups leads to decarboxylation of LA and formation of free radicals, which can initiate the polymerization (Scheme 1). A similar decarboxylation process was previously reported in photoinduced polymerization using semiconductor metal oxide NPs in the presence of carboxylic acids as co-initiators. ${ }^{29}$ Moreover, in one-component thioxanthone photoinitiators specially designed with the carboxylic acid group, decarboxylation also occurs as a consequence of a hydrogen abstraction by photoexcited thioxanthone moieties. ${ }^{41-43}$

In order to confirm the suggested decarboxylation of LA, a model reaction in the absence of a monomer was conducted. Thus, a dispersion of $\mathrm{Fe}_{3} \mathrm{O}_{4}$-LA NPs in toluene $(3 \mathrm{~mL})$ was placed in a quartz tube connected to another one containing an aqueous solution of sodium carbonate $\left(4.7 \times 10^{-3} \mathrm{M}\right)$ with phenolphthalein. Upon irradiation of the NP solution at $350 \mathrm{~nm}$, the pink solution of sodium carbonate became colorless indicating the decarboxylation of the LA moiety causing carbon dioxide evolution and consequently sodium bicarbonate formation (Fig. 4). 


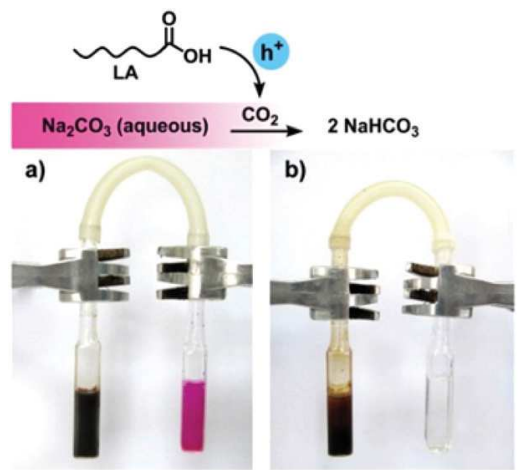

Fig. 4 Visual observation of discoloration of the aqueous solution of sodium carbonate with phenolphthalein as a result of decarboxylation of lauric acid by the photogenerated holes from $\mathrm{Fe}_{3} \mathrm{O}_{4}$-LA NPs: (a) before and (b) after irradiation. The phenolphthalein solution is in the right-hand side tube.

Analysis of the irradiated NPs by FTIR showed a reduction in the intensity of the characteristic peaks of the carboxylic acid moiety of LA in the irradiated NPs compared with fresh NPs due to the decarboxylation process (Fig. 5).

When using TEA as the co-initiator, oxidation of TEA by the hole followed by a hydrogen abstraction from another TEA molecule, is possibly responsible for the generation of initiating TEA radicals (Scheme 2).

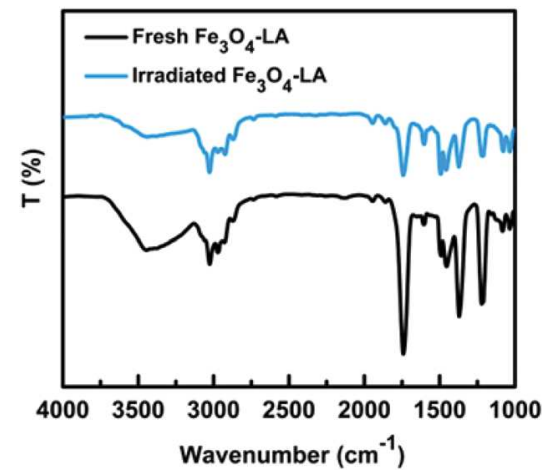

Fig. 5 FTIR spectra of fresh (bottom) and irradiated (top) $\mathrm{Fe}_{3} \mathrm{O}_{4}$-LA NPs.

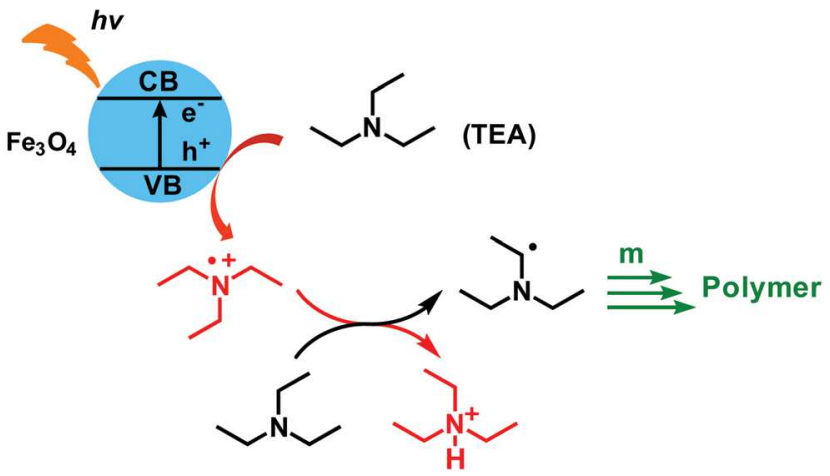

Scheme 2 Proposed initiation mechanism of the photopolymerization of vinyl monomers using $\mathrm{Fe}_{3} \mathrm{O}_{4}$ - LA NPs in the presence of the triethylamine co-initiator.
Overall, in the presence of a TEA co-initiator possibly both radicals generated on the coating molecules and TEA are responsible for the initiation. Of course, partial ligand exchange of LA with TEA is also possible.

\section{Conclusions}

We have demonstrated that semiconductor NPs are efficient photoinitiators for free radical polymerization of vinyl monomers. $\mathrm{Fe}_{3} \mathrm{O}_{4}$ NPs with acidic agents were prepared and successfully utilized in the photoinitiation of free radical polymerization. The NPs acted as one-component photoinitiators through the interaction of the photogenerated holes by oxidizing capping agents to yield initiating radicals. However, the addition of a tertiary amine co-initiator resulted in an increase in the efficiency of the system. To the best of our knowledge, this work is the first example on the use of magnetic $\mathrm{Fe}_{3} \mathrm{O}_{4}$ NPs as photoinitiators in polymerization processes. There is clearly a scope for further investigations on the described systems. Further studies in developing other types of semiconductor NPs as photoinitiators together with further understanding of the initiation mechanisms of individual systems are now in progress.

\section{Acknowledgements}

This work is dedicated to the late Professor Anthony Ledwith, former president of the Royal Society of Chemistry. The authors acknowledge financial support from the Istanbul Technical University Research Fund.

\section{Notes and references}

1 D. M. Adams, L. Brus, C. E. D. Chidsey, S. Creager, C. Creutz, C. R. Kagan, P. V. Kamat, M. Lieberman, S. Lindsay, R. A. Marcus, R. M. Metzger, M. E. MichelBeyerle, J. R. Miller, M. D. Newton, D. R. Rolison, O. Sankey, K. S. Schanze, J. Yardley and X. Y. Zhu, J. Phys. Chem. B, 2003, 107, 6668-6697.

2 F. Wen and C. Li, Acc. Chem. Res., 2013, 46, 2355-2364.

3 R. Gill, M. Zayats and I. Willner, Angew. Chem., Int. Ed., 2008, 47, 7602-7625.

4 A. Hagfeldt, G. Boschloo, L. C. Sun, L. Kloo and H. Pettersson, Chem. Rev., 2010, 110, 6595-6663.

5 M. R. Hoffmann, S. T. Martin, W. Y. Choi and D. W. Bahnemann, Chem. Rev., 1995, 95, 69-96.

6 H. Zhang, G. Chen and D. W. Bahnemann, J. Mater. Chem., 2009, 19, 5089-5121.

7 H. Kisch, Angew. Chem., Int. Ed., 2013, 52, 812-847.

8 Y. Qu and X. Duan, Chem. Soc. Rev., 2013, 42, 25682580.

9 D. Tunc and Y. Yagci, Polym. Chem., 2011, 2, 25572563. 
10 H. Tar, D. S. Esen, M. Aydin, C. Ley, N. Arsu and X. Allonas, Macromolecules, 2013, 46, 3266-3272.

11 J. Zhang, M. Frigoli, F. Dumur, P. Xiao, L. Ronchi, B. Graff, F. Morlet-Savary, J. P. Fouassier, D. Gigmes and J. Lalevee, Macromolecules, 2014, 47, 2811-2819.

12 S. C. Ligon, B. Husar, H. Wutzel, R. Holman and R. Liska, Chem. Rev., 2014, 114, 557-589.

13 R. Pynaert, J. Buguet, C. Croutxe-Barghorn, P. Moireau and X. Allonas, Polym. Chem., 2013, 4, 2475-2479.

14 Y. Yagci, S. Jockusch and N. J. Turro, Macromolecules, 2010, 43, 6245-6260.

15 J.-P. Fouassier and J. Lalevee, Photoinitiators for Polymer Synthesis: Scope, Reactivity and Efficiency, Wiley-VCH, Weinheim, 2012.

16 B. Kiskan, J. Zhang, X. Wang, M. Antonietti and Y. Yagci, ACS Macro Lett., 2012, 1, 546-549.

17 G. Yilmaz, B. Iskin, F. Yilmaz and Y. Yagci, ACS Macro Lett., 2012, 1, 1212-1215.

18 Z. J. Wang, K. Landfester and K. A. I. Zhang, Polym. Chem., 2014, 5, 3559-3562.

19 S. Dadashi-Silab, H. Bildirir, R. Dawson, A. Thomas and Y. Yagci, Macromolecules, 2014, 47, 4607-4614.

20 M. Yamaoto and G. Oster, J. Polym. Sci., Part A: Polym. Chem., 1966, 4, 1683.

21 A. J. Hoffman, H. Yee, G. Mills and M. R. Hoffmann, J. Phys. Chem., 1992, 96, 5540-5546.

22 S. Dadashi-Silab, A. M. Asiri, S. B. Khan, K. A. Alamry and Y. Yagci, J. Polym. Sci., Part A: Polym. Chem., 2014, 52, 15001507.

23 S. Dadashi-Silab, M. A. Tasdelen, A. M. Asiri, S. B. Khan and Y. Yagci, Macromol. Rapid Commun., 2014, 35, 454-459.

24 S. Dadashi-Silab, M. A. Tasdelen, B. Kiskan, X. C. Wang, M. Antonietti and Y. Yagci, Macromol. Chem. Phys., 2014, 215, 675-681.

25 J. Yan, B. Li, F. Zhou and W. Liu, ACS Macro Lett., 2013, 2, 592-596.
26 B. Li, B. Yu and F. Zhou, Macromol. Rapid Commun., 2014, 35, 1287-1292.

27 S. Dadashi-Silab, M. A. Tasdelen and Y. Yagci, J. Polym. Sci., Part A: Polym. Chem., 2014, 52, 2878-2888.

28 N. C. Strandwitz, Y. Nonoguchi, S. W. Boettcher and G. D. Stucky, Langmuir, 2010, 26, 5319-5322.

29 Z. Weng, X. Ni, D. Yang, J. Wang and W. Chen, J. Photochem. Photobiol., A, 2009, 201, 151-156.

30 N. C. Strandwitz, A. Khan, S. W. Boettcher, A. A. Mikhailovsky, C. J. Hawker, T.-Q. Nguyen and G. D. Stucky, J. Am. Chem. Soc., 2008, 130, 8280-8288.

31 A. L. Stroyuk, V. M. Granchak, A. V. Korzhak and S. Y. Kuchmii, J. Photochem. Photobiol., A, 2004, 162, 339-351.

32 D. Zhang, J. Yang, S. Bao, Q. Wu and Q. Wang, Sci. Rep., 2013, 3, 1399-1405.

33 A. P. Alivisatos, J. Phys. Chem., 1996, 100, 13226-13239.

34 X. C. Cai, K. C. Anyaogu and D. C. Neckers, J. Am. Chem. Soc., 2007, 129, 11324-11325.

35 X. C. Cai, K. C. Anyaogu and D. C. Neckers, Chem. Commun., 2008, 5007-5009.

36 K. C. Anyaogu, X. C. Cai and D. C. Neckers, Macromolecules, 2008, 41, 9000-9003.

37 X. C. Cai, K. C. Anyaogu and D. C. Neckers, Photochem. Photobiol. Sci., 2009, 8, 1568-1573.

38 H. Y. Acar, R. S. Garaas, F. Syud, P. Bonitatebus and A. M. Kulkarni, J. Magn. Magn. Mater., 2005, 293, 1-7.

39 D. Zhang, J. Yang, S. Bao, Q. Wu and Q. Wang, Sci. Rep., 2013, 3, 1399-1406.

40 A. J. Hoffman, G. Mills, H. Yee and M. R. Hoffmann, J. Phys. Chem., 1992, 96, 5546-5552.

41 M. Aydin, N. Arsu and Y. Yagci, Macromol. Rapid Commun., 2003, 24, 718-723.

42 M. Aydin, N. Arsu, Y. Yagci, S. Jockusch and N. J. Turro, Macromolecules, 2005, 38, 4133-4138.

43 G. Yilmaz, B. Aydogan, G. Temel, N. Arsu, N. Moszner and Y. Yagci, Macromolecules, 2010, 43, 4520-4526. 